\title{
İç Mekanda Doku Etkisinin Kurgulanmasında Tasarımcı Yaklaşımlarının İncelenmesi
}

\author{
Onur Kılıç ${ }^{*}$ \\ ${ }^{1}$ Çukurova Üniversitesi, Mimarlık Fakültesi, İç Mimarlık Bölümü, Adana, Türkiye (ORCID: 0000-0001-6264-896X)
}

(İlk Geliş Tarihi 31 Ocak 2020 ve Kabul Tarihi 31 Mart 2020)

(DOI: 10.31590/ejosat.682979)

ATIF/REFERENCE: Kılıç, O. (2020). İç Mekanda Doku Etkisinin Kurgulanmasında Tasarımcı Yaklaşımlarının İncelenmesi. Avrupa Bilim ve Teknoloji Dergisi, (18), 858-867.

\section{$\ddot{O} \mathbf{z}$}

Doku, yüzeylere tanım getiren bir tasarım öğesidir. Bu tanım, mimari açıdan kullanıcı algısını şekillendiren renk, biçim ve 1şık öğelerinin tasarıma olan etkilerini tamamlamaktadır. Bu önemi nedeniyle iç mekanda doku, bir tasarım öğesi olarak tasarımcıların özgünlüğünü oluşturan önemli unsurlardan biridir. Bu çalışmada, doku kavramı tanımlanarak doğal ve yapay doku türlerine değinilmiştir. Doğal süreçler sonunda oluşan doku etkilerinin dışında, bilgisayar destekli tasarım ve dijital üretim teknikleri ile yapılan doku tasarımı, mekan örnekleri üzerinden değerlendirilmiştir. Tasarım unsurları kullanılarak mekanda yaratılan doku etkileri ve renk, ışık, biçim değişkenlerinin dokuya olan etkileri, bilgisayar destekli tasarım ile hazırlanan sanal mekanlar üzerinden yorumlanmıştır. Böylelikle değişen renk ve biçimin, doku algısında yarattığı değişimin ortaya konulması amaçlanmıştır. Çalışmada, iç mekan tasarımındaki doku kullanım farklılıklarının ifade edilebilmesi için, tasarımcıların bu konudaki yaklaşımları mekan örnekleri üzerinden değerlendirilmiştir. Bu değerlendirme, iç mekan tasarımlarında doku kullanımı ile öne çıkan tasarımcıların özgün yaklaşımlarını ve dokunun tasarım öğesi olarak iç mekanda kullanılma biçimlerini ortaya koymayı amaçlamaktadır. İncelenen örnekler, doku kullanımı açısından tasarımcıların özgün yaklaşımlarını yansıtan örnekler arasından seçilmiştir. Buna göre, değerlendirilen tasarımcılar arasında yer alan Karim Rashid'in doğal dokular yerine, kendi tasarladığı yapay dokuları kullandığı görülmüştür. Philippe Stark'ın ise, malzemenin doğal dokusunu iç mekanda tercih ettiği, Fernández de la Hoz'un ise iç mekanda yer alan bir çok yüzeyde, biçim ve ışığın etkisini doku oluşumunda kullandığı görülmüsşür. İç mekanda dokunun kullanım biçimi ve tercih edilen yüzeyler açısından da tasarım dilinin değişsenlik gösterdiği tespit edilmiştir. Bu bulgular sonucunda, iç mekanda dokunun yalnızca tasarımın önemli bir parçası değil, aynı zamanda tasarımcıların özgünlüğünü oluşturan bir kimlik unsuru olduğu değerlendirilmektedir.

Anahtar Kelimeler: Doku, İç Mekan, Tasarım, Tasarımcı

\section{An Analysis on Designer Approaches in Creating Texture Effect in Interior Space}

\begin{abstract}
Texture is an element of design defining the surfaces. This definition completes the effects of color, form and light elements shaping the perception of users in terms of architecture on design. Due to this importance, texture in interior space, as an element of design, is one of the important elements that makes up the uniqueness of designers. In this study, the concept of texture is defined, and natural and artificial types of texture are addressed. In addition to the effects of texture as a result of natural processes, texture design created by computer-aided design and digital production techniques is evaluated through space samples. The texture effects created in the space using design elements and the effects of color, light and form variables on texture are interpreted through virtual spaces created by computer-aided design. Thus, the aim is to reveal the change created by the changing color and form in the perception of texture. In the study, approaches of designers are evaluated through space samples in order to display the differences of texture use in the interior design. This evaluation aims to reveal the unique
\end{abstract}

\footnotetext{
* Sorumlu Yazar: Çukurova Üniversitesi, Mimarlık Fakültesi, İç Mimarlık Bölümü, Adana, Türkiye, ORCID: 0000-0001-6264-896X,
} 
approaches of designers standing out with the use of texture in the interior space designs and the ways that texture is used in interior space as an element of design. The examined samples were selected from the ones reflecting the unique approaches of designers in terms of texture use. Accordingly, it has been observed that Karim Rashid one of the designers evaluated in the study prefers to use artificial textures he designed rather than natural textures. On the other hand, it has been observed that Philippe Stark prefers the natural texture of material in interior space while Fernández de la Hoz uses the effects of form and light in the texture formation on various surfaces in interior space. It has been found that design language also varies in terms of the use of texture and the preferred surfaces in interior space. In the light of these findings, it is considered that texture in interior space is not only an important part of design, but also an element of identity that makes up the uniqueness of designers.

Keywords: Texture, Interior Space, Design, Designer

\section{Giriş}

Doku kavramının farklı bilim dallarındaki ifadesi ve tanımı değişmektedir. En genel haliyle doku, birimlerin bir örüntü oluşturacak şekilde bir araya gelmesiyle oluşan bir özellik olarak tanımlanabilir. Bu özellik, mikro ya da gözle tanımlanabilecek şekilde makro boyutta iki veya üç boyutlu etkilere de sahip olabilmektedir. Mimaride ise makro boyutta tasarımı etkileyen görsel öğe olarak ele alınarak tasarımcılar tarafindan yorumlanmaktadır.

Mimarinin geçirdiği dönüşüm ele alındığında, mimari yönelimleri tanımlayan en önemli unsurlarından birinin "doku" olduğu görülmektedir. Örneğin barok dönemi mimari yaklaşımında özellikle iç mekanda tasarımı şekillendiren yoğun bir doku algısı zihinlerde oluşmaktadır. Bu doku algısını, yüzeylerde kullanılan renklerin ve süslemelerin oranı, iç mekan öğelerinin ve aydınlatma elemanlarının biçimsel özellikleri oluşturmaktadır. Bu durumu, mimarinin tüm dönemlerinde farklı şekilde görebilmek mümkündür. Ancak günümüzde, gelişmiş özelliklere sahip malzemeler, dijital üretim, biçimlendirme teknikleri ve tasarım anlayışının geldiği nokta "doku" kullanımını farklı bir boyuta taşımıştır. Dokunun tasarım öğesi olarak geldiği bu boyut, dokunun tasarımcılar tarafından bir kimlik ve imza olarak da kullanımı da ifade etmektedir. Bu kapsamda, dokunun iç mimari tasarım açısından ifade ettikleri, kullanıcı algısındaki olası etkileri ve tasarımcı yaklaşımlarının öneminin ortaya konulması gerekmektedir. Bu amaçla, öncelikle doku kavramı, doku algısını etkileyen değişkenler ve iç mekanda tasarım öğesi olarak doku kullanımını etkileyen faktörlerin açıklanması gerekli görülmektedir.

\section{Materyal ve Metot}

\subsection{Doku}

Tabiatta gerçek doku daima bir fonksiyonun ifadesidir. İnsan yapısı objelerde de ancak böyle olduğu zaman doku bir değer kazanmaktadır. Bu konuda da insanoğlu en büyük örneklerini tabiattan almaktadır. Tabiatta canlı ve cansız tüm varlıklar birçok fonksiyonunu çeşitli dokuların kullanımı ile yerine getirmişlerdir. Sayısız örnekler arasından bir tanesi de korunma fonksiyonunu sert ve batıcı dokularla yerine getiren bitki ve hayvanlardır (Tüzcet, 1967; Oransay, 2006). Coates ve diğerleri (2011)'e göre doku bir nesnenin uyandırdığı histir: Pürüzlü, pürüzsüz, yumuşak veya sert. Doku aynı zamanda bir mekanın karakter ve özelliklerini tanımlamak için de kullanılabilir. Bir mekanın dokusu, kullanılan malzeme ya da nesneler ile belli kültürel referanslar ya da belli fikirlere yapılan göndermeler ile manipüle edilebilir (s.70). Şekil 1'de doğal doku örnekleri yer almaktadır.
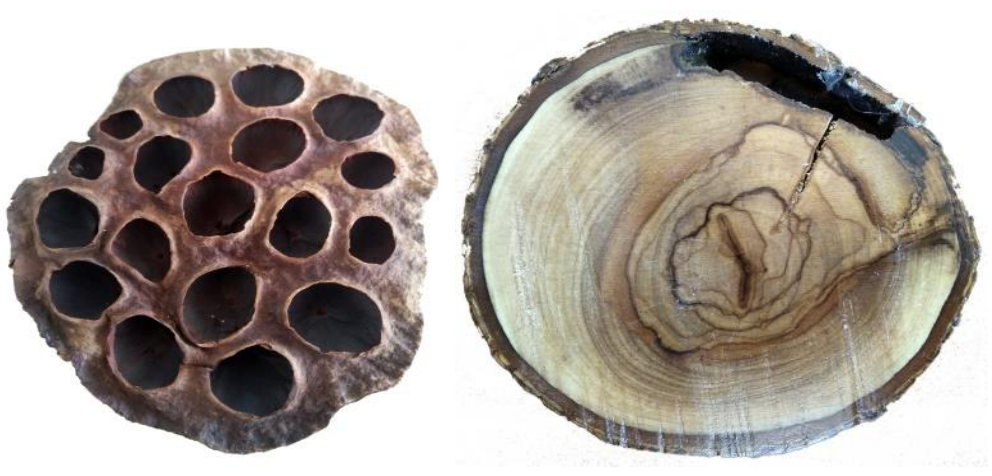

Şekil 1. Doğal doku örnekleri (Kıllı̧, 2020)

Doku etkisi yanlızca bir yüzeyde hacimsel olarak değil aynı zamanda ışık gölge gibi etkenlerin etkisiyle de oluşabilmektedir. Bu oluşumları da doğal doku olarak tanımlamak mümkündür. Şekil 2'de ahşap elemanların tekrarının yarattığı doku etkisi görülmektedir. Tekrar oranı ve boyutu arttıkça ortaya çıkan algısal etkide değişmektedir. 

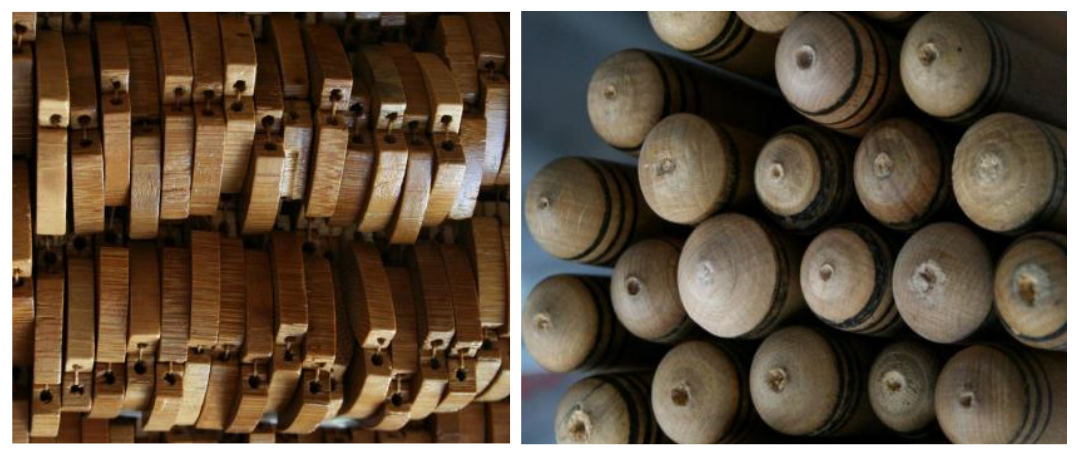

Şekil 2. Birim tekrarının oluşturduğu doku etkisi (Kılıç, 2020)

Renk, doku, ton (1şıklılık değerı), biçim, ölçü, aralık (espas) doğanın nesnel yapısında varolan öğelerdir. Anlam, içerik, kapsam, işlev ve psikolojik olarak doğa dilinin, plastik yaşama yansımalarıdır. Yine zıtlık, uygunluk, yineleme (tekrar), simetri, koram, egemenlik ilkeleri; doğanın yapılanış ve biçimleniş ilkeleridir (Atalayer, 2004 s.14). Doku, bir yüzeyin pürüzlülüğü ve pürüzsüzlüğ̈̈dür. Yüzey pürüzlü, pürüzsüz, sert, yumuşak, parlak ve mat olabilir (Michael, 2011 s.28). Bir nesnenin yüzeyinin dokusu mekansal algiy1 etkilemektedir (Castell vd. 2019 s.1).

Doku etkisi yanlızca bir yüzeyde hacimsel olarak değil aynı zamanda ışık gölge gibi etkenlerin devreye girmesiyle de oluşabilmektedir. Bu oluşumları doğal doku olarak adlandırabiliriz. Doğal dokular düzenli, düzensiz ve değişken dokular olmak üzere üç gruba ayrılmaktadır. İç mekanda ise yapay dokular tasarımcı tercihine bağlı olarak öne çıkabilmektedir. Özellikle bilgisayar destekli tasarımın yaygınlaşması ile yapay dokuların tasarımı mümkün hale gelmiş̧ir. Bilgisayar destekli tasarımın yanısıra dijital üretim teknikleri de doku tasarımlarının üretilmesini sağlamaktadır (Şekil 3).
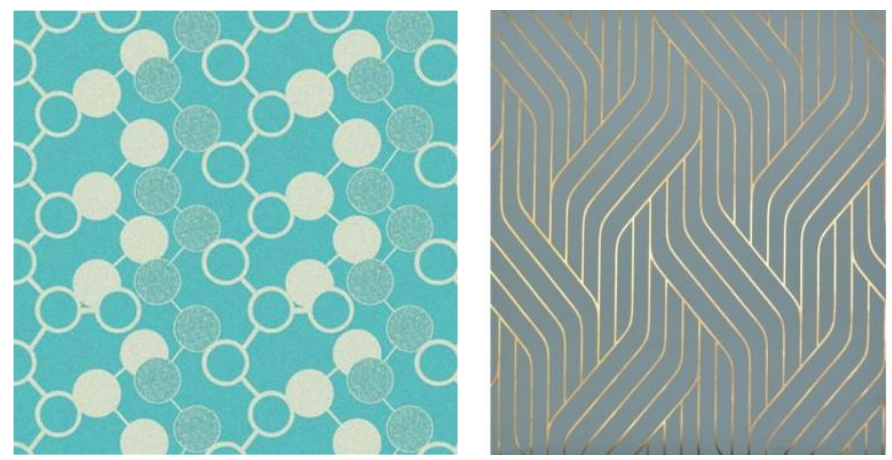

Şekil 3. Yapay doku örnekleri [1,2]

Yapay dokulara bir çok farklı sektörde ihtiyaç duyulmaktadır. Doku tasarımlarında kullanılan nesnenin veya yüzeyin işlevsel olması, tasarıma değer katmaktadır. İç mekan tasarımı açısından ise kullanışlı yapı ürünlerini örnek vermek mümkündür.

Temel tasarımda ise doku, tasarımın ana bileşenlerinden birini oluşturmaktadır. Buna bağlı olarak temel tasarımın ana prensiplerinin malzeme ve üretim teknolojileri kullanılarak uygulanması, iç mekanda istenilen etkilerin elde edilmesini sağlamaktadır. Bu etkilerden biri olarak doku, tasarımcıların kullandığı önemli tasarım unsurları arasındadır.

\subsubsection{Doku Algısını Etkileyen Değişkenler}

Baş (2001)'e göre doğa ile tanıştığı ilk andan itibaren insanın en sık rastladığı ağaç, taş, toprak gibi doğal öğeler, yüzey olarak kullanılmaları ile oluşturulan mekan tasarımlarında da, kullanıcının görsel algılama süreci içinde en kolay ve en hızlı tanımladığı dokusal ifadeleri oluşturmaktadır (s.41).

Dokuyu şekillendiren tekrar, ritim, denge ve vurgu faktörlerinin dışında renk, ışık, ve biçim faktörleri de dokunun oluşumunda etkilidir. İç mekanda kurgulanan doku etkisi, farklı sşık şiddeti, geliş yönü veya ışı̆̆ın rengi ile büyük oranda değişebilmektedir. Öte yandan dokuyla bir bütün olan renk kavramı da değişiklik gösterdiğinde aynı türde olan dokular farklı şekilde algılanabilmektedir. Biçim etkeninde ise farklı biçimlere sahip yüzeylerde aynı doku etkileri farklı algılanabilmektedir. Bu noktada, kullanıcının tasarımı okuyabilme veya yorumlayabilme kabiliyetinin de değişkenlik gösterdiği unutulmamalıdır.

Doku etkisinin güçlü veya zayıf olarak algılanmasında renk faktörü belirleyicidir. Örneğin birimlerin tekrarı ile oluşan doku etkisinin renk değişimi sonucu farklılaştığı görülmektedir. Beyaz renkteki birimlerin tekrarının daha zayıf bir doku etkisi yarattığı, ancak siyah renk kullanıldığında doku etkisinin güçlendiği değerlendirilmektedir (Şekil 4). 


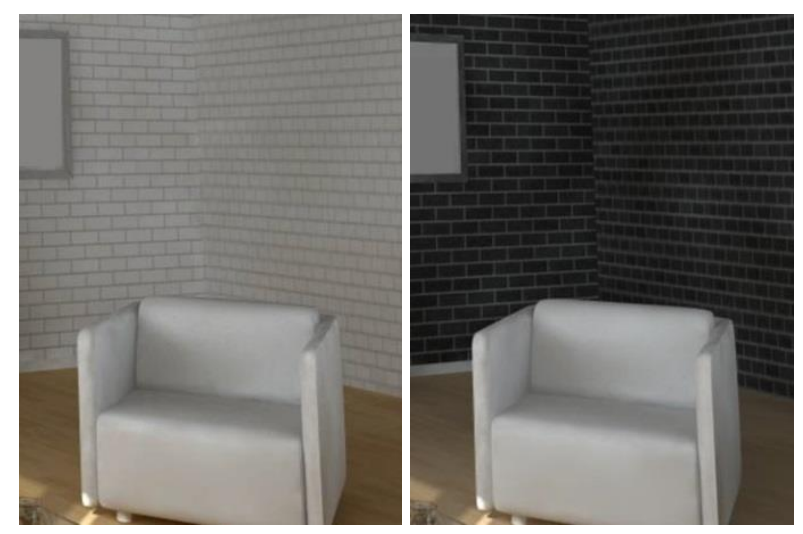

Şekil 4. Duvar yüzeyinde birimlerin tekrarıyla oluşan dokuya rengin etkisi (Kılıç, 2020)

Taylor (2000)'e göre doku, bir hacimde iki şekilde kullanılabilir: Bir hacmin belirli bir bölgesel veya tarihi stili ifade etmesi için; ya da cesur bir şekilde, dokunun hacmin ana odağ gelmesi ise ise rengin doğru kullanımı ile mümkündür. Şekil 5 'te de aynı birim tekrarında farklı renklerin kullanıldığı görülmektedir. Aynı bakış açısında, açık mavi renk kullanılan örnekte olan doku etkisi zayıf olarak algılanırken, kırmızı rengin kullanımı ile dokunun yoğun bir etki yaratarak mekanda öne çıktığı görülmektedir.
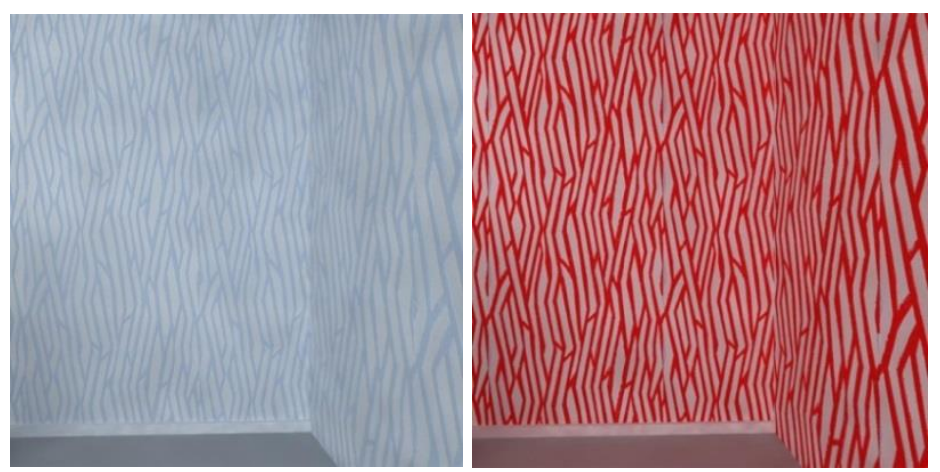

Şekil 5. Duvar yüzeyindeki doku algısının farklı renkler ile gösterdiği değişkenlik (Kılıç, 2020)

Işığın, iç mekan tasarımında hacimlerin algılanmasında önemli bir rolü vardır. Işık algı açısından hacmin fiziksel olarak niteliğini ve niceliğini doğrudan değiştirmektedir. Örneğin, görsel tanımlama yapılabilecek kadar aydınlatılmayan bir mekanın tasarım açısından istenen etkiyi yaratması mümkün değildir. Aynı şekilde 1şık düzeyi doğru olmayan bir hacimde kullanıcıların konforunun sağlanması da mümkün değildir. Dokuyla ilişkisi açısından ise doğal ışı̆̆ın biçimle birlikte kullanımı ise, genel ve lokal aydınlatma yaklaşımları, doku etkilerini oluşturabilmektedir. Bunun dışında sşık, doku algısında da aydınlatma düzeyinin yeterliliği açısından etkilidir.

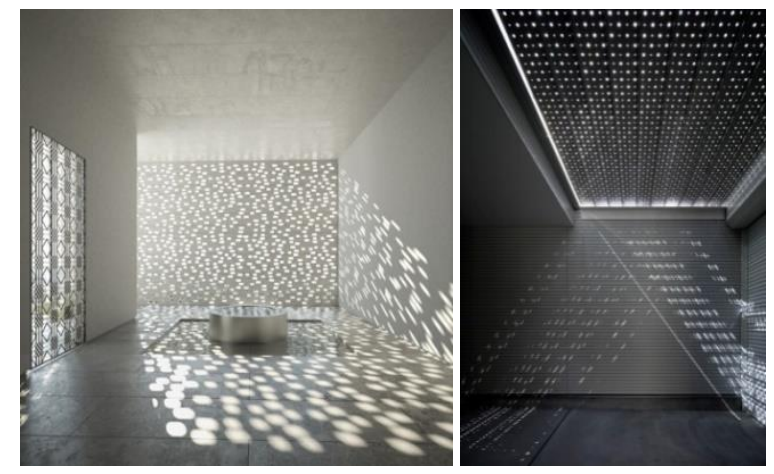

Şekil 6. Biçim ve ışı̆̆ın birlikte oluşturduğu doku etkisi $[3,4]$

Malzemelerin biçimlendirmeye elverişli olması, her biçimlendirmede malzemenin dokusal ifadesinde farklı düzenlemelere gidilmesine sebep olmaktadır. Bu durum ifadesizlikten, anlam sapmalarına kadar her türlü anlatımın yaratılmasında bu malzemelerin daha çok kullanılmasını sağlamaktadır (Baş, 2001 s. 69). Buna göre, biçim ve doku ilişkisinin tasarımla ve yaratılmak istenen anlamla doğrudan ilişkisi vardır. Buradaki farklılığı, tasarımcıların özgün yaklaşımları olarak değerlendirmek mümkündür. 
İç mekanda farklı biçimler kullanılarak oluşturulan yapı elemanları ve donatılar, dokunun algılanmasında farklılık yaratabilmektedir. Aynı iki boyutlu dokunun, farklı biçim üzerine uygulanmasıyla, doku üç boyutlu hale dönüşerek algıda farklılık ortaya çıkmasını sağlamaktadır. Şekil 7'de iç mekanda kullanılan separatörün aynı iki boyutlu doku ile farklı biçimlerde kullanımı görülmektedir.
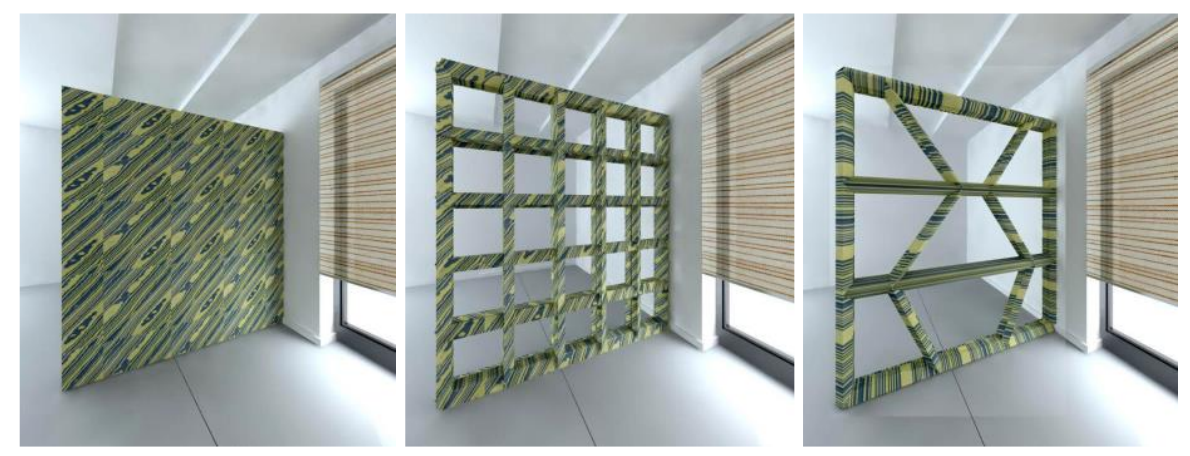

\subsection{2.İç Mekanda Tasarım Öğesi Olarak Doku Kullanımını Etkileyen Faktörler}

Şekil 7. Biçimin doku algısına etkisi (Kıllıc, 2020)
Oarak Doku Kullanımını Etkileyen Faktörler

Teknoloji, tüm yapım sürecini hızlandıracak ve kolaylaştıracak imkanları tasarımcılara sunmaktadır. Bu nedenle önceki dönemlerde üretilmesi veya uygulanması mümkün olmayan ya da çok zor olan tasarımlar günümüzde kolaylıkla elde edilebilmektedir. Özellikleri geliştirilmiş kompozit yapı ürünleri, yenilikçi bağlantı yöntemlerinin yanı sıra bilgisayar destekli tasarım ve dijital üretim teknolojileri bu gelişmenin lokomotifi rolündedir. İç mekan tasarımında donatıların ve yapı elemanlarının tasarımı bilgisayar destekli tasarımın etkisiyle günümüzde oldukça çeşitlenmiştir. Yapılan tasarımların eşzamanlı olarak görülebilmesi ve üzerinde anında değişiklik yapılarak farklı form, biçim ve renklerin denenebilmesi tasarım sürecini hızlandırmıştır. Bilgisayar destekli tasarım imkanı zaman kaybını azaltarak, tasarımın birebir elde edilebilmesini sağlamaktadır. Bu bağlamda, iki ve üç boyutlu çizim ve tasarım programları bilgisayar destekli tasarımın temelini oluşturmaktadır.

Şekil 8'de bilgisayar destekli tasarım ile oluşturulan ve üretilen zemin kaplama malzemeleri görülmektedir. Sayısal ortamda yapılan tasarım hata olasılığını düşürmekte ve hassas ölçülendirme ile üretim yapabilme imkanı sunmaktadır. Benzer doku etkileri zemin ve duvar yüzeylerinin dışında iç mekandaki tüm yüzeylerde ve donatılarda, kısmı veya bir bütün oluşturacak şekilde kullanılabilir.
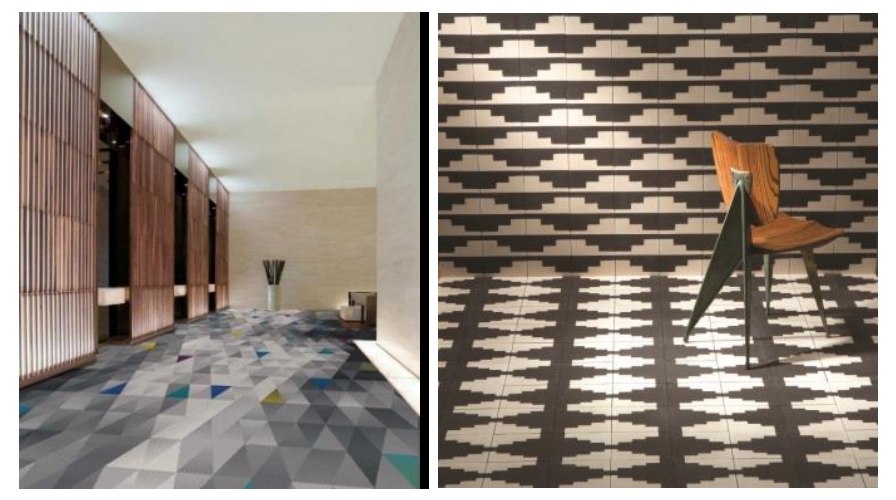

Şekil 8. Farklı renk, biçim ve tekrarın kullanımı ile zeminde ve duvarda doku etkisi [5,6]

Ahşap kompozit türlerinin yanı sıra, doğal ahşap türleri de doku etkisi nedeniyle tasarımcılar tarafindan. tercih edilmektedir. Malzemenin kendi yüzey dokusunun yanı sıra, birim tekrarının oluşturduğu doku etkisi tasarımın parçasını oluşturmaktadır. Şekil 9'da ahşap elemanların düşeyde ve yatayda kullanımı ile elde edilen doku etkileri görülmektedir. Düşeyde ahşap birimlerin düzensiz tekrarı ile elde edilen doku etkisinin mekanlarda sınırlayıcı olarak kullanıldığı görülmektedir. Bununla birlikte, ahşap malzemenin kendine has dokusunun mekanda sıcak bir atmosfer yaratılmasına yardımcı olmaktadır. 

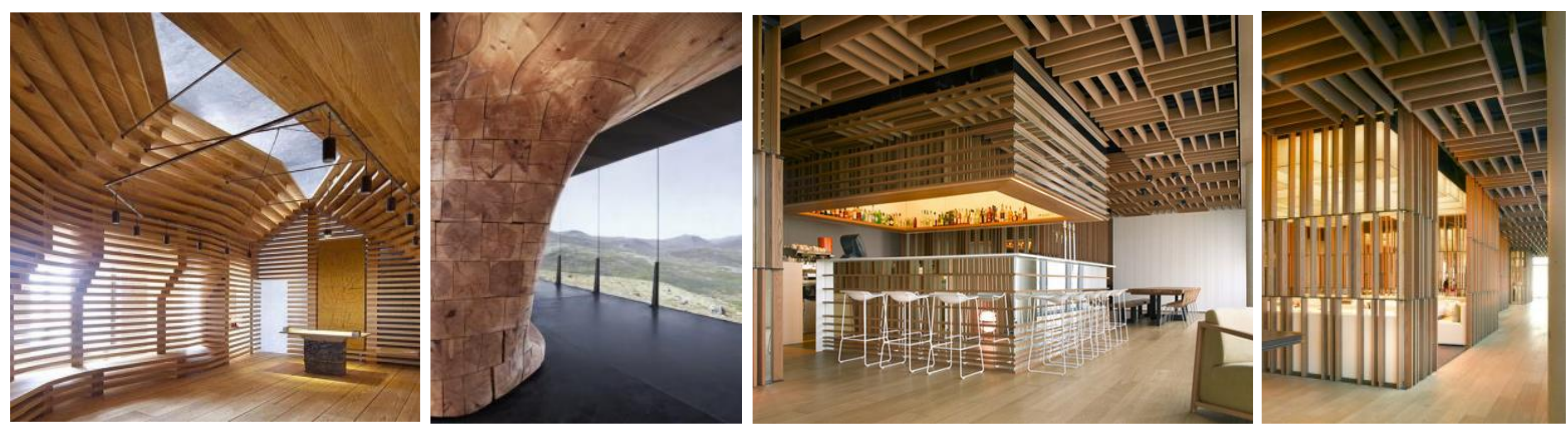

Şekil 9. Birim tekrarı ile oluşan doku etkisi [7,8,9]

Doku etkisine sahip tekstil yapı ürünlerinin dijital üretim teknikleriyle üretimi yaygındır. Özellikle bilgisayar destekli tasarım yoluyla iki boyutlu olarak yapılan tasarımların malzeme üzerine dokuma ya da baskı yoluyla aktarılması iç mekanda kullanımını sağlamaktadır. Özellikle günümüzde nano teknolojinin kullanımı yalnızca görsel olarak değil aynı zamanda fiziksel özelliklere de sahip tekstil ürünlerin elde edilmesini sağlamaktadır. Nano teknoloji sayesinde, akıllı olarak adlandırılan tekstil malzemeler aynı zamanda sağlık açısından olumlu etkilere sahip olmaktadır. Isıya duyarlı, su geçirimsiz, nefes alabilen, kendi kendini temizleyebilen, ve yıpranmama özellikleri ile nano tekstil malzemeler iç mekanda tercih edilmektedir.
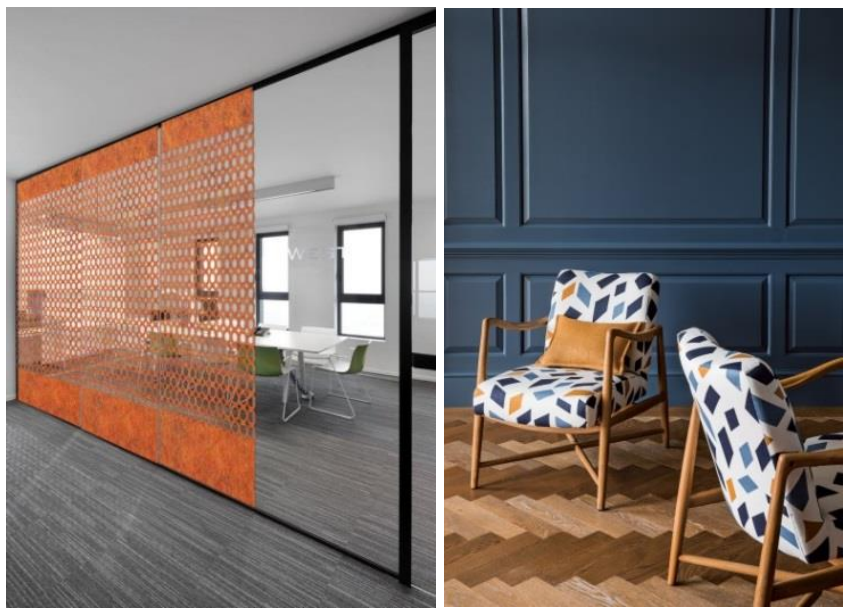

Şekil 10. Doku etkisine sahip tekstil yüzeyler [10,11]

İç mekan tasarımda kullanılan tekstil malzemelerin mekan atmosferine etkisi, kullanım oranına ve doku özelliklerine de bağlı olarak yüksektir. Yoğun desen içeren bir tasarım karmaşık ve yorucu olarak algılanırken, daha sade tasarımlar kullanıcı üzerinde dinlendirici bir etki yaratabilir. Tekstil malzemeler genel olarak iç mekanda mobilyalarda, duvar ve tavan yüzeylerinde, aydınlatmalarda ve separatör olarak kullanılmaktadır.

\section{Araştırma Sonuçları ve Tartışma}

\section{1. İç Mekanda Dokunun Kurgulanmasında Tasarımcı Yaklaşımları}

İç mekanda dokunun kullanımında, tasarımcıların kendilerine özgü tasarım yaklaşımları ön plana çıkmaktadır. Tasarımcılar, iç mekanda doku etkisinin oluşumunda malzemenin sahip olduğu doğal dokuyu farklı şekillerde kullanmanın yanısıra, bilgisayar destekli tasarım ve dijital üretim metodları ile oluşturulmuş yapay dokuları da yoğun biçimde kullanmaktadır. Örneğin çalışma kapsamında incelenen tasarımcılar arasında yer alan Karim Rashid, yapay doku kullanımını benimsemektedir. Zemin, duvar kaplama malzemelerini ve donatılarda kullanılan tekstil malzemelerin dokularını tasarlayarak iç mekan tasarımlarında bir imza niteliğinde kullanmaktadır. Bu yaklaşım, tasarımııın iç mekan tasarımının biçimlenişinde dokuyu etkili bir tasarım aracı olarak kullandığını göstermektedir. Şekil 11 'de Karim Rashid'in tasarladığı yüzeyler görülmektedir. 


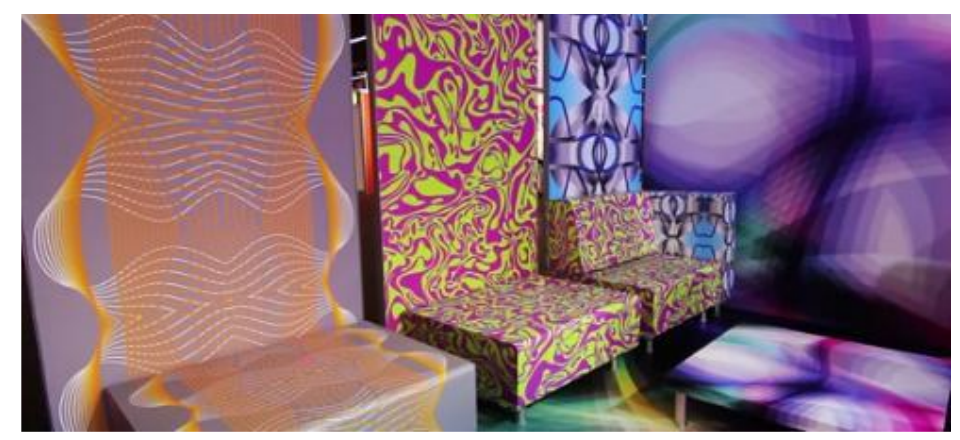

Şekil 11. Karim Rashid tasarım sergisi, Frankfurt- Karim Rashid [12]

Karim Rashid, yüzeylerde çok sayıda farklı desen motif ve renk kullanmaktadır. Desen ve motiflerin oluşumunda bilgisayar destekli tasarımdan yararlanılmaktadır. Ürünün elde edilebilmesi için ise dijital üretim teknikleri kullanılmaktadır. Tekstil ve kağıt malzeme üzerine baskı yöntemi tasarımcının en çok kullandığı yöntem olarak öne çıkmaktadır. Karim Rashid, bilgisayar destekli tasarımın dışında aynı zamanda birim tekrarını ve biçimi kullanarak da iç mekanda doku etkisi elde etmektedir.

Şekil 12'de girişi tanımlayan duvar yüzeyindeki doku etkisi dikkat çekmektedir. Diğer görsel de duvar yüzeyinde oluşturulan hareketli biçimin gizli aydınlatmanın katkısı ile bir doku etkisi yarattı̆̆ı görülmektedir. Zemindeki malzeme farkı, dokuyu ve oluşan görsel etkiyi desteklemektedir.
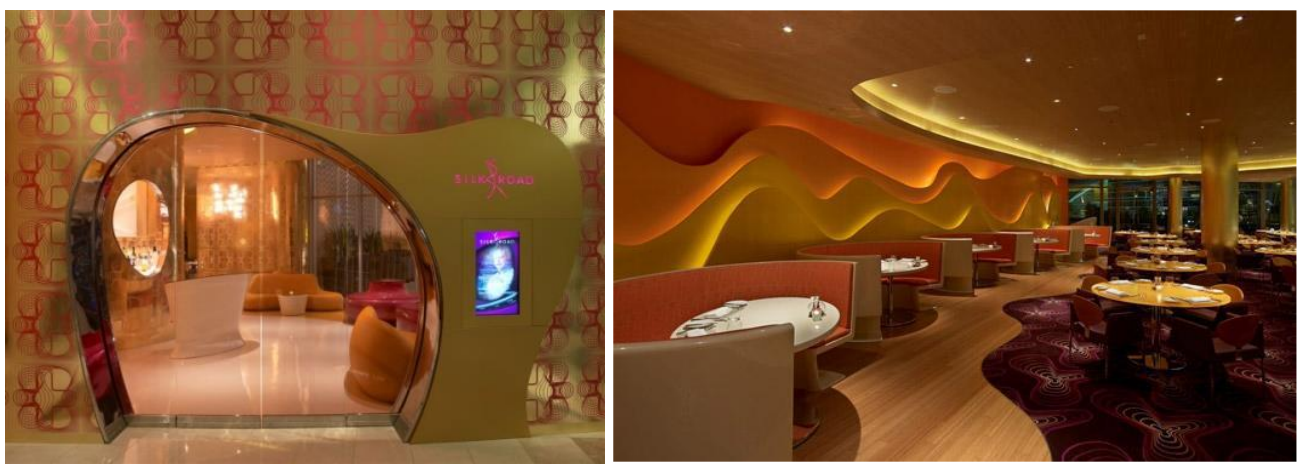

Şekil 12. Silk Road Restorant, Las Vegas- Karim Rashid [12,13]

Şekil 13'de duvar yüzeylerinde biçimlerin tekrarı ve renk geçişleri ile oldukça güçlü bir doku etkisi elde edildiği görülmektedir. Duvar yüzeylerinde noktasal aydınlatmayı çağrıştıran yapı ve organik yüzey algısı yaratan dalgalı öğeler, bir bütün olarak doku etkisini oluşturmaktadır. Bu doku etkilerinin oluşumunda biçimin ve ışığın etkisini görmek mümkündür. Ayrıca tavanda kullanılan yazılar da kendi içinde diğer dokulardan farklı bir etki yaratarak tasarım yaklaşımını desteklemektedir. Genel olarak bu tasarımda kullanıcıların dokuların oluşturduğu bir kabuğun içerisinde kendilerini hissetmelerinin amaçlandığını söylemek mümkündür.
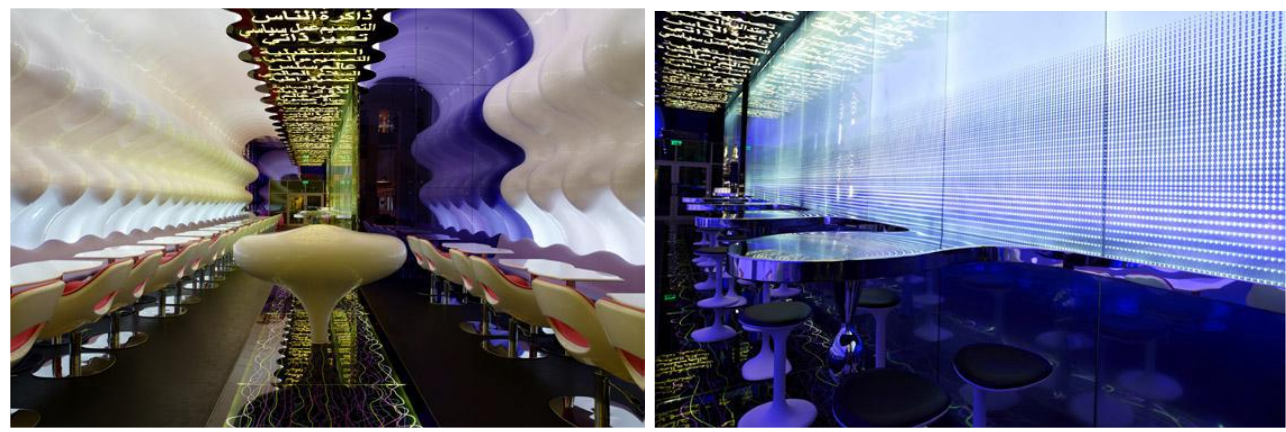

Şekil 13. Switch Restorant Restorant, Dubai- Karim Rashid [12]

Şekil 14'teki tasarımda yapay dokuların kullanım yoğunluğu açısından farklı bir yaklaşım bulunmaktadır. İ̧ mekanda, neredeyse nötr yüzey olmaksızın tüm yüzeylerde ve donatılarda yoğun şekilde, bilgisayar destekli tasarım ile oluşturulan yapay dokuların kullanıldığı görülmektedir. Özellikle altıgen biçiminde tasarlanan oturma alanlarında, farklı renk, desen ve birim tekrarının kullanımı, bu yaklaşımı ifade etmektedir. Bu anlayış iç mekan tasarımını kurgulayan tasarım öğeleri açısından, dokunun en belirleyici tasarım unsuru olarak tercih edildiğini göstermektedir. Mekan kimliğinin parçası olarak bu noktada dokunun işlevi, kullanıcıya algılatılmak istenen atmosferin oluşmunda en belirleyici rolü üstlenmektedir. 

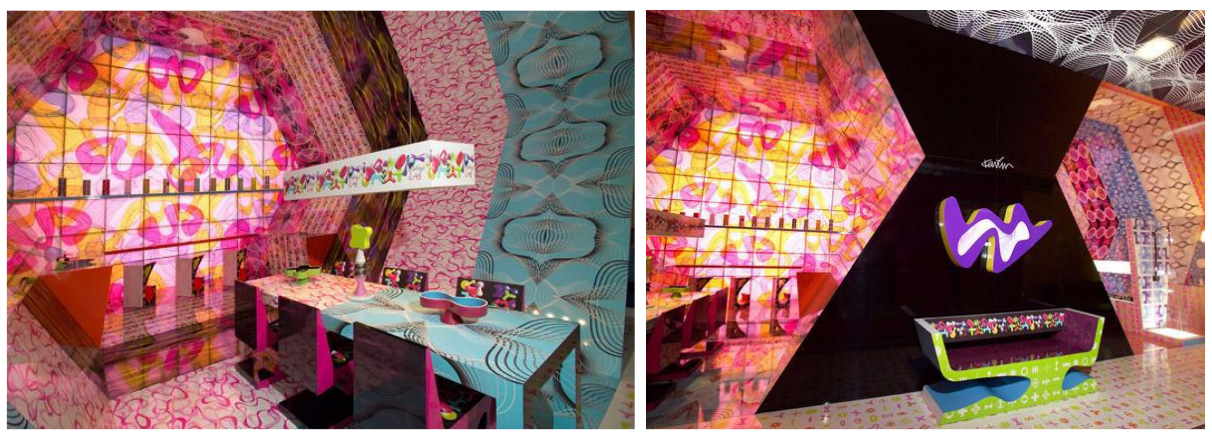

Şekil 14. Casa Digitalia, Milan- Karim Rashid [12]

Philippe Stark, tasarım yaklaşımında doku kullanımı açısından yapay doku kullanımını tercih eden Karim Rashid'den farklı olarak, malzemelerin doğal dokularını kullanmayı tercih etmektedir. Doğal malzemelerin tekrarı ile yüzey oluşturma ve biçimin doku oluşumunda kullanımı, tasarım yaklaşımının temelini oluşturmaktadır. Bununla birlikte karmaşadan uzak sınırlı sayıda renk kullanımı, dokunun oluşmunda tasarımcının diğer bir yaklaşımı olarak değerlendirilmektedir. Şekil 15'te, Philippe Stark'ın bir iç mekan tasarımı yer almaktadır. Tasarımda tekstil malzeme seperatör olarak kullanılmış ve malzemenin doğal dalgalı biçimsel yapısı birim tekrarı oluşturarak doku etkisi meydana getirmiştir. Dokunun oluşumunda kullanılan renk sayısı, yoğunluğu ve yüzeydeki toplam oranı tasarımı doğrudan etkilemektedir. Bu örnekte doku etkisi tek renk kullanımı ile biçimin etkisi öne çıkarılarak oluşturulmuştur. Bu tasarım örneğini, dokuyu etkileyen faktörlerden rengin kullanımı açısından sade, ancak biçimin doku oluşumundaki rolü bakımından yoğun doku etkisine sahip bir örnek olarak değerlendirmek mümkündür.
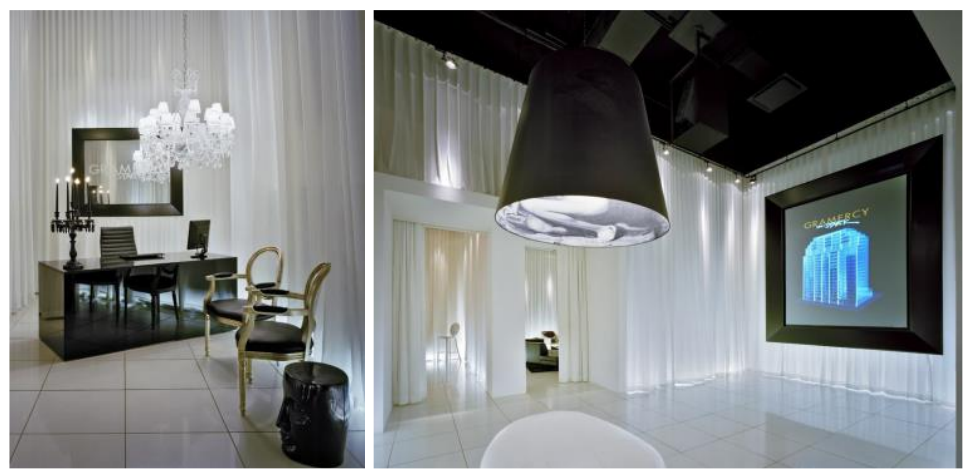

Şekil 15. Yoo Gramercy, NewYork- Philippe Starck [14]

Şekil 16'da Philippe Stark'ın tüm duvar ve tavan yüzeylerinde ahşap dokusu kullandığı tasarımı yer almaktadır. Yoğun şekilde kullanılan doğal ahşabın mekanda sıcak bir atmosfer yarattığı görülmektedir. Buradaki tasarım yaklaşımı, bir önceki iç mekan tasarım örneğinde olduğu gibi malzemenin sahip olduğu dokuyu herhangi bir müdahale olamadan kullanmayı ifade etmektedir. Bilgisayar destekli tasarım ile üretilen yapay dokuların kullanıcılarda oluşturduğu yapaylık algısının aksine, doğal dokuların kullanımı ve oluşan doğal mekan etkisi tasarımcının benimsediği özgün bir yaklaşım olarak değerlendirilmektedir.
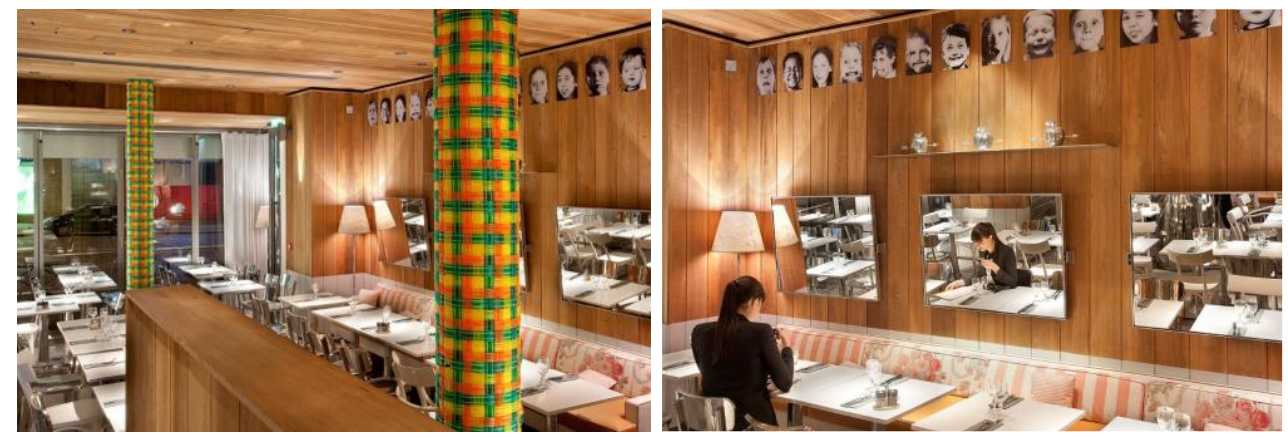

Şekil 16. Paradis de Fruit, Paris- Philippe Starck [14]

Fernández de la Hoz, iç mekanın kurgulanmasında dokuyu tasarım öğesi olarak kullanmaktadır. İncelenen diğer iki tasarımcının aksine Fernández de la Hoz’un doku yaklaşımında, birim tekrarı ve ışı̆̆ın kullanımı öne çıkmaktadır. Bu bağlamda, Matedero Film Kütüphanesi iç mekandaki doku etkileriyle dikkat çekmektedir (Şekil 17). Aydınlatmanın düşeyde ve yatayda çeşitli yapı elemanlarıyla birlikte kullanımı, tasarımdaki doku etkisini güçlendirmektedir. Burada benimsenen doku yaklaşımı, 1şık ve birim 
tekrarının yoğun şekilde kullanımı ile şekillenmektedir. Düşey yüzeylerdeki katmanlı yapı da derinlik algısını artırarak, kullanıcıların dokuyu güçlü şekilde algılamasını sağlamaktadır. Dokunun mekan tasarımına fonksiyonel etkisi açısından da yatayda birimlerin tekrarıyla sınırlandırılmış boşluk, başka bir bölüme geçişi tanımlamaktadır.
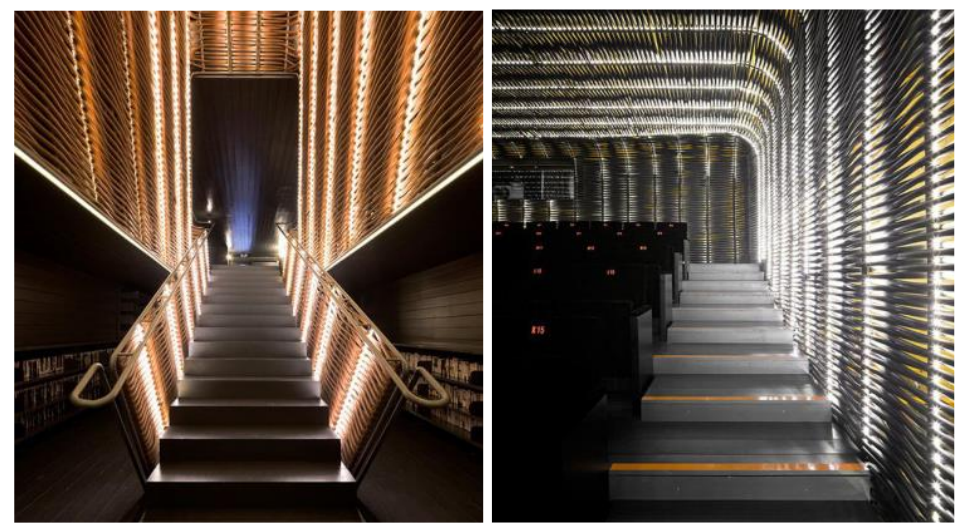

Şekil 17. Matedero Film Kütüphanesi, Madrid-Fernández de la Hoz [15]

Tasarımcıların doku kullanımındaki yaklaşımlarını ortaya koymak için incelenen örnek sayısını artırmak mümkündür. Ancak tasarımcıların yaklaşım farklıılıklarının ifade edilmesi için sınırlı sayıda örnek yeterli olabilmektedir. Bu bağlamda, incelenen örneklerde görüldüğü gibi iç mekanda doku kullanımında tasarımcıların birbirlerinden farklı yaklaşımları olduğu açıktır. Bu farklılık tasarımcıların özgünlüğünü oluşturan tasarım yaklaşımlarını şekillendirmektedir.

\section{Sonuç}

Her yüzeyin farklı ve ancak yarattıkları etki ile birbirinden ayrılan doku etkisi vardır. Bu etkiler mimaride tasarım öğesi olarak kullanıcıların algısını yönlendirmektedir. Bu kapsamda, algıyı etkileyen faktörler olan renk ve biçim değişkenlerinin dokuya olan etkileri bilgisayar destekli tasarım ile oluşturulan sanal mekanlar üzerinden değerlendirilmiştir. Buna göre sıcak veya soğuk renkler ile aynı yüzeyin dokusunun farklı şekilde algılandığı, biçimin doku algısına olan güçlendirici veya zayıflatıcı etkileri olduğu görülmüştür. Işık şiddetinin doku algısını etkilemesi, biçim ve ışı̆̆ın birleşimi ile doku etkisinin oluşması da diğer bulgular arasındadır. Bununla birlikte dokuların bilgisayar destekli tasarım ve dijital üretim tekniklerinin sunduğu hız ve hataları revize edebilme imkanı ile elde edilebildiği görülmüştür. Özellikleri geliştirilmiş malzemelerin de doku tasarımında bir faktör olarak öne çıktığı görülmüştür.

Tasarımcıların iç mekanda doku kullanım yaklaşımları ise, bazı mekan tasarımları üzerinden incelenmiştir. İncelenen örnekler, doku kullanımı açısından tasarımcıların özgün yaklaşımlarını yansıtan örnekleri kapsamaktadır. Bu inceleme neticesinde, tasarımcı Karim Rashid'in hazır malzeme dokusunu kullanmak yerine, bilgisayar destekli tasarım ile dokuyu tasarlayarak kullandığı görülmüştür. Bu yaklaşım tasarımcının iç mekan kurgusunda abartılı doku etkilerinin kullanımına imkan vermektedir. Philippe Stark'ın ise tasarımlarında rengin sınırlı kullanımı ile malzemelerin doğal dokusunu kullanmayı tercih ettiği görülmüsstür. İncelenen diğer bir tasarımcı olan Fernández de la Hoz’un ise özellikle düşey yüzeylerde katmanlı bir yapı oluşturarak birim tekrarı ve 1şığın etkin kullanımı ile doku etkileri oluşturduğu görülmüştür. Bununla birlikte Hoz’un dokuyu mekan içerisindeki alanları tanımlamak için de kullanarak, görsel etkilerin ötesinde dokuya işlevsel bir amaç da yüklediği değerlendirilmiştir. Tasarımcılar arasında görülen tüm bu yaklaşım farklılıkları neticesinde, iç mekanda dokunun kullanım biçiminin birbirinden ayrışı̆̆̆ tespit edilmiştir. Tüm bu bulguların ışığında, iç mekanda dokunun yalnızca tasarımın önemli bir öğesi değil, aynı zamanda tasarımcıların özgünlüğünü oluşturan ve tasarımı şekillendiren bir kimlik unsuru olduğu değerlendirilmektedir.

\section{Kaynakça}

Atalayer, F. (2004), Çağdaş Temel Sanat (Tasarım) Eğitimi ve Postmodernite-Geleneksellik, Anadolu Üniversitesi Dergileri, Anadolu Sanat, Sayı:15, Eskişehir.

Baş, D. (2001) Yüzeylerin Dokusal İfadeleri ile Mekan Kimliğinin Oluşturulmasında Yapısal Çözümlemeye Dayanan Bir Yöntem Önerisi, Sanatta Yeterlik Tezi, Mimar Sinan Üniversitesi, Fen Bilimleri Enstitüsü, İstanbul.

Castell, C. Hecht, H. ve Oberfeld, D. (2019) Wall patterns influence the perception of interior space, Quarterly Journal of Experimental Psychology, DOI: 10.1177/1747021819876637.

Coates, M., Brooker, G., Stone, S., (2011) Görsel İç Mimarlık Sözlüğü, Literatür Kitapevi.

Faullener, R., Ziegfield, E., Hill, G., 1956, Art Today, Henry Holt and Company, New York

Guidot, R., 2006. Industrial Design Techniques and Materials, Flammarion, Paris

Kocks, U.F., Tome, C.N., Wenk, H.R., 1998. Texture and Anisotropy, Cambridge University Press, Cambridge

Taylor, R. (2000) İnterior Colour: The Secrets the İnterior Style, Cassell\&Co, London.

Michael M. (2011) Art and Design: A Comprehensive guide for Creative Artist.

Oransay, L. (2006) Doku, strüktür ve tekrar ilkelerinin seramik alanında kullanım olanakları, Sanatta Yeterlik Tezi, Anadolu Üniversitesi, Sosyal Bilimler Enstitüsü, Eskişehir. 
European Journal of Science and Technology

Tüzcet, Ö. (1967) Form ve Doku, Matbaa Teknisyenleri Kollektif Şirketi, İstanbul, 1967.

\section{Internet Kaynakları}

[1] https://tr.pinterest.com/pin/429741989419410992/

[2] http://0fs.me/8363067

[3] http://leibal.com/architecture/light-grain/

[4] https://www.dezeen.com/2009/10/29/486-mina-el-hosn-by-lan-architecture/

[5] http://www.contemporaryrugs.eu/hallway-modern-rugs-want-fall/

[6] https://www.architecturaldigest.com/gallery/kitchen-tile-sources-guides

[7] http://www.tasarimdergisi.com/etkinlik.php?id=436

[8] http://0fs.me/6275956

[9] http://0fs.me/3837199

[10] http://Ofs.me/4735269

[11] http://0fs.me/9087108

[12] http://www.karimrashid.com/

[13] https://www.contemporist.com/silk-road-by-karim-rashid/

[14] http://www.starck.com/

[15] http://mitademo.com/mimarlik/matadero-film 